\title{
Validation of decisional balance inventory test in Italian: assessment of motivation in weight loss
}

\author{
Anna Giulia Falchi, ${ }^{1}$ Chiara Muggia, ${ }^{1}$ Ilaria Grecchi, ${ }^{1,2}$ Ilaria Michelini, ${ }^{1}$ Annalisa De Silvestri, ${ }^{3}$ Carmine Tinelli ${ }^{3}$ \\ ${ }^{1}$ Department of Internal Medicine, Clinica Medica II - IRCCS Foundation, Policlinico San Matteo, Pavia; ${ }^{2}$ Experimental \\ Medicine, University of Pavia; ${ }^{3}$ Clinical Epidemiology and Biometric Unit, IRCCS Foundation, Policlinico San Matteo, Pavia, Italy
}

\begin{abstract}
The decisional balance inventory (DBI) test is a valuable tool to assess motivation to change; we consider its application in enhancing motivation of losing weight. Our aim is the translation, cultural adaption and validation in Italian of this test originally designed and drafted in English. The questionnaire has been translated according to an English $\rightarrow$ Italian $\rightarrow$ Italian $\rightarrow$ English algorithm with reconciliation of the differences. Pilot study and retests were performed on 47 cases [body mass index (BMI) $\left.\geq 30 \mathrm{~kg} / \mathrm{m}^{2}\right]$ and 15 controls (BMI value between 18.5 and $25 \mathrm{~kg} / \mathrm{m}^{2}$ ). The internal consistency of the Italian version of DBI test, was satisfied (Cronbach $\alpha 0.87$ on patients); test-retest shows a good concordance in pilot [Lin's concordance correlation coefficient (CCC) 0.79; 95\% confidence interval (CI) 0.68-0.90] and in patient sample (Lin's CCC 0.83; 95\% CI: 0.67 0.99).Our study demonstrated the trans-cultural adaptation and validation of DBI test in Italian.
\end{abstract}

\section{Introduction}

\section{Weight loss motivation dimensionality}

The modification of eating habits is considered an integral part of the treatment of various chronic diseases such as obesity, ${ }^{1}$ diabetes, ${ }^{2}$ hypertension, ${ }^{3}$ dyslipidaemia, ${ }^{4}$ ischemic heart disease and heart failure. ${ }^{5}$ The techniques used today to encourage improvements in eating habits focus on patients training, in order to enable them

Correspondence: Anna Giulia Falchi, Clinica Medica II IRCCS Foundation, Policlinico San Matteo, p.le Golgi 19, 27100 Pavia, Italy.

Tel.: +39.0382.502090 - Fax: +39.0382.502441.

E-mail: a.falchi@smatteo.pv.it

Key words: Validation; decisional balance inventory; motivation to change; obesity.

Contributions: AGF, IG, manuscript drafting; IM, CM, clinical and psychological aspects management; CT, ADS, statistical analysis performing.

Conflict of interest: the authors declare no conflict of interest.

Received for publication: 8 June 2014 .

Revision received: 18 March 2015.

Accepted for publication: 22 April 2015.

This work is licensed under a Creative Commons Attribution NonCommercial 3.0 License (CC BY-NC 3.0).

(C) Copyright A.G. Falchi et al., 2015

Licensee PAGEPress, Italy

Italian Journal of Medicine 2015; 9:268-272

doi:10.4081/itjm.2015.520 to make responsible alimentary choices. Such approaches include motivational interviewing, techniques for impulse control, use of nutritional counselling and cognitive-behavioral techniques ${ }^{6}$ as well as an educational action aimed to improve knowledge about food composition, function and utilization. Purely cognitive intervention, though in itself not sufficient to change behavior, is a fundamental pre-requisite for any nutritional program. It is evident that the analysis of motivation to change is crucial to understand the patient compliance in following diet prescription, thus influencing the course of therapy. The assessment of obese patients motivation is recommended in national and European guidelines for obesity treatment. ${ }^{7}$ Besides many theories or schools of counseling (e.g., cognitive behavior therapy, psychodynamic approaches, humanistic therapies, etc.), readiness to change has been studied in detail by Prochaska and Velicer ${ }^{8,9}$ who developed the transtheoretical model of behavior change (TTM): it is yet one of the most accepted models for assessing the readiness to change. It has been applied to different lifestyle changes, as reported in a recent review showing at least 48 fields of application..$^{10}$ Despite the near-unanimous agreement between clinicians and researchers about the evaluation and the intervention on weight loss patients motivation, there is a surprising lack of studies both in the conceptualization and in the research field.

\section{Justification of the study}

Janis and Mann $(1968,1977)^{11}$ elaborated the gain versus loss model by identifying a decisional balance sheet of comparative potential gains and losses. Two decisional balance measures, the pros and the cons, have become critical constructs in the TTM. The pros 
and cons combine to form a decisional balance sheet of comparative potential gains and losses. The balance between the pros and cons varies depending on which stage of change the individual is in. The decisional balance inventory (DBI) test was historically conceptualized by Janis and Mann (1977) and then devised by O'connell and Velicer (1988) ${ }^{12}$ as a valuable tool to assess motivation to change. Although it has never been validated in Italian before, it is currently used to investigate the motivation in weight loss, ${ }^{13,14}$ and it is also recommended by some Italian scientific societies dealing with feeding. ${ }^{15}$ Since the Italian National Health Service encourages the use of concrete evidence and scientifically proven tools and treatments, an Italian version validation of DBI questionnaire becomes imperative: this psychological interview represents in fact a useful aid in basal assessment of patients seeking for weight loss treatment. The simple translation of a questionnaire may lead to misinterpretation due to language and cultural differences: besides the translation into Italian, it is necessary to carry out a cross-cultural adaptation, and its psychometric properties need to be confirmed..$^{16}$ The aim of the current investigation is the translation, cultural adaption and validation in Italian of this test originally designed and drafted in English.

\section{Materials and Methods}

\section{Participants}

We recruited a normal weight [body mass index (BMI) value between 18.5 and $\left.25 \mathrm{~kg} / \mathrm{m}^{2}\right]$ non-clinical sample of 15 adult subjects ( 14 females, 1 male) (controls) and a clinical sample of 47 adult subjects ( $33 \mathrm{fe}-$ males, 14 males) with obesity (body mass index, BMI $>$ or $\left.=30 \mathrm{~kg} / \mathrm{m}^{2}\right)$ (cases). Demographic data are shown in Table 1. All the subjects did not suffer from any psychiatric disease and also in the past they had never dealt with a mental illness diagnosis; besides they declared to have never taken any psychiatric medication.

\section{Instrument: structure of the test}

In clinical practice, the motivation to change lifestyle is an important factor in influencing the course of therapy. DBI was used to estimate the decisional balance in losing weight. It is a self-adminis- tered questionnaire based on the decision making theory, a component of the TTM of Prochaska; this is one of the most accepted models for assessing the readiness to change. DBI test consists of 20 items, 10 representing processes that benefit weight loss and 10 representing factors that hinder the loss of weight (respectively called pros and cons). A five point Likert scale was used for each item, ranging from 1 (not important) to 5 (extremely important). Subjects were asked to rate the importance of each statement in influencing their decision whether or not to lose weight. The score is calculated by the ratio between the sum of the cons and the pros. If the ratio is high, it means that there are more cons and the readiness to change is low. The cut off is considered as a score $>1.5$. DBI test has been generally used only as a screening instrument without any diagnostic value.

\section{Procedures}

\section{Translation and cultural validation process}

The validation procedure is composed of three steps: translation-back translation procedure, pilot study, and verification of the test-retest reliability.

First step: translation was performed according to the standards outlined by the STARD (standards for reporting of diagnostic accuracy) guidelines. ${ }^{17}$ The DBI test was translated from the original language (English) into Italian by two native Italian speakers (IM, AGF) who were fluent and had a clear understanding of conceptual meanings in both English and Italian. The two translations were compared by the coordinator (CM) of the study and discrepancies were resolved by discussion, and a single translation was generated. This version was then back translated by two native independent English (SP-IP) speakers who were also fluent in Italian. These were evaluated by the coordinator and compared with the original version to ensure conceptual equivalence of the translation. The goal of the translation and adaption was to develop a version of the DBI that sounded natural in Italian, conceptually equivalent to the original English version and easy to understand and to answer for Italian patients. The translation and adaption algorithm was performed in accordance with the international quality of life assessment (IQOLA) project approach. ${ }^{18}$

Second step: the pilot study. The pilot test was con-

Table 1. Population characteristics.

\begin{tabular}{lccccc}
\hline & $\begin{array}{c}\text { Employment status, } \\
\text { no. of employed (\%) }\end{array}$ & $\begin{array}{c}\text { Educational diploma, } \\
\text { no. (\%) }\end{array}$ & $\begin{array}{c}\text { Attainment degree, } \\
\text { no. (\%) }\end{array}$ & $\begin{array}{c}\text { Marital status, } \\
\text { no. of married (\%) }\end{array}$ & $\begin{array}{c}\text { Age, } \\
\text { mean (SD) }\end{array}$ \\
\hline Cases & $34(72.3 \%)$ & $10(21.3 \%)$ & $30(63.8 \%)$ & $37(78.7 \%)$ & $50(11)$ \\
\hline Controls & $15(100 \%)$ & $4(26.7 \%)$ & $8(56.3 \%)$ & $9(60 \%)$ & $38(9.6)$ \\
\hline
\end{tabular}

$\mathrm{SD}$, standard deviation. 
ducted mainly in order to identify and solve any potential problem in the translation, such as wording that might be confusing or difficult to understand. The controls [14 females and 1 male of 15 adult normal weight subjects (BMI value between 18.5 and $25 \mathrm{~kg} / \mathrm{m}^{2}$ )] and the cases [47 adult subjects ( 33 females, 14 males) with obesity $\left.\left(\mathrm{BMI}>\mathrm{or}=30 \mathrm{~kg} / \mathrm{m}^{2}\right)\right]$ were asked to complete the Italian version of the DBI test.

Third step: to measure the test-retest reliability, the controls and the cases were re-contacted after an average of 8 days for a second assessment of DBI test.

\section{Ethical statement}

This study was conducted in conformity with the Declaration of Helsinki ${ }^{19}$ and an informed consent was obtained prior to the completion of the questionnaire in accordance with the directions of the local ethics committee (Policlinico San Matteo Ethics Committee). The test was administrated in a self-reported fashion (i.e., the administrator did not assist the subjects in the compilation of the questionnaire).

\section{Statistical analyses}

Quantitative variables were normally distributed (Shapiro test) and so the results were expressed as mean values and standard deviation (SD); qualitative variables were summarized as counts and percentages. The internal consistency reliability of the scale was determined by calculating Cronbach's $\alpha$; it ranges from 0 to 1 , with 1 indicating perfect reliability and a value $\geq 0.70$ an acceptable reliability. ${ }^{20}$ Agreement on a continuous measure is expressed through Lin's ${ }^{21,22}$ concordance correlation coefficient (CCC). The CCC combines measures of both precision and accuracy to determine how far the observed data deviate from the line of perfect concordance (that is, the line at 45 degrees on a square scatter-plot). Lin's coefficient increases in value as a function of the nearness of the data's reduced major axis to the line of perfect concordance (the accuracy of the data) and of the tightness of the data about its reduced major axis (the precision of the data). The CCC can be expressed as the product of $r$ (the measure of precision: i.e., Pearson correlation coefficient) and $\mathrm{C} \_\mathrm{b}$ (i.e., the bias-correction factor, the measure of accuracy); the interpretation of Lin's coefficient was similar to the one reported below for kappa-statistic. In patient sample, the concordance for single items was analyzed with Cohen's kappa-statistic, ${ }^{23}$ a measure of agreement for categorical values: it is scaled to be 0 when the amount of agreement is what expected by chance and 1 when there is perfect agreement. For intermediate values, Landis and $\mathrm{Koch}^{24}$ suggest the following interpretations: below 0.0 poor, 0.00-0.20 slight, 0.21-0.40 fair, 0.41-0.60 moderate, 0.61-0.80 substantial, 0.81-1.00 almost perfect. Comparisons between patients and controls were analyzed with $t$ test for independent data. $\mathrm{P}<0.05$ was considered statistically significant. Data analysis was performed with STATA statistical package (release 13, 2013; Stata Corp., College Station, TX, USA).

\section{Results}

\section{Reliability - Internal consistency}

Cronbach $\alpha$ was 0.87 in the patient sample; the range was 0.85 to 0.88 ; no single item was found to change substantially the internal consistency.

\section{Readability and time for compilation}

The questionnaire is composed of short and straightforward items. It is easy to read and to understand. The average time required for compilation is about $10 \mathrm{~min}$.
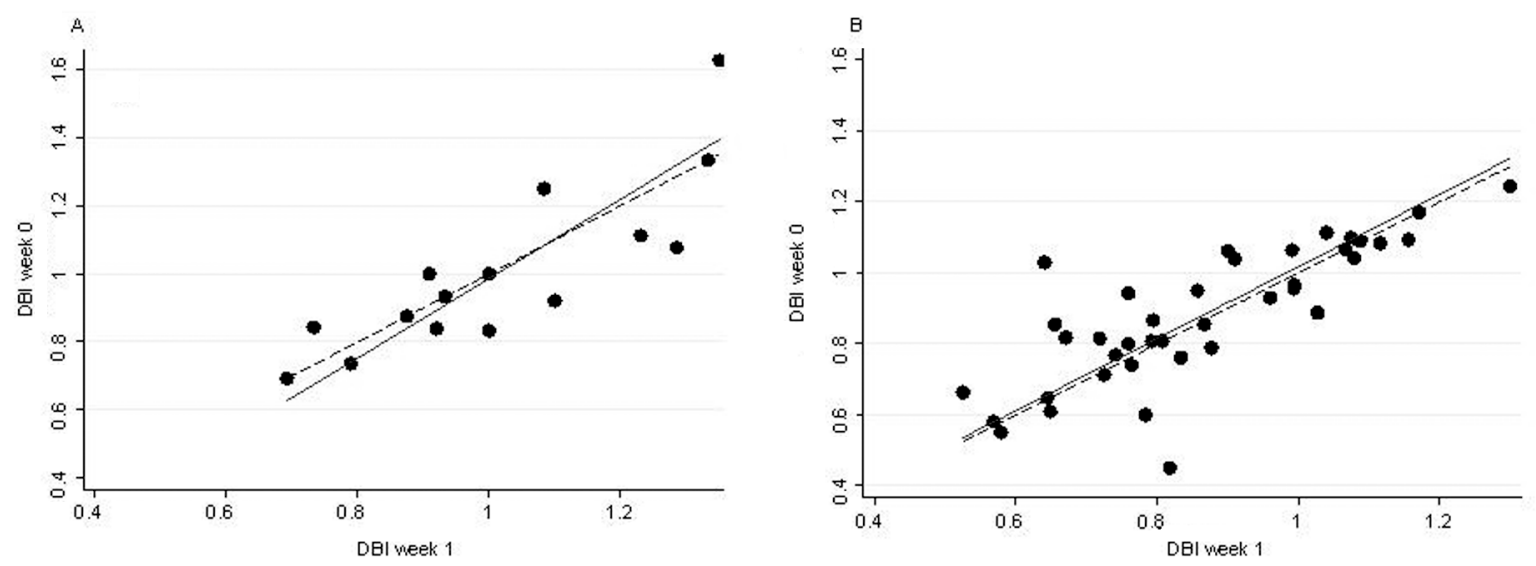

Figure 1. Decisional balance inventory (DBI) global score concordance between baseline and a week later for (A) controls and (B) patients. The dashed line is the line of perfect agreement. 


\section{Pilot test on controls}

All the 15 subjects completed the test easily, not needing help or clarification. No problems were found in translations, such as wording that might be confusing or difficult to understand. DBI mean global score was 1.01 (SD: 0.25) at baseline and 1.02 (SD: 0.21) a week later; Lin's CCC was 0.79 [95\% confidence interval (CI) $0.68-0.90]$, $r$ was 0.81 and C_b 0.97 (Figure 1A). Similar results were obtained with sum of cons (CCC 0.77, r 0.78 and C_b 0.99) and sum of pros (CCC 0.73, r 0.74, C_b 0.996).

\section{Test-retest results in patients}

DBI mean global score was 0.75 (SD: 0.25 ) at baseline and 0.73 (SD: 0.28$)$ after retest.

Lin's CCC was 0.83 (95\% CI: 0.668 0.993); Pearson $\mathrm{r}$ was 0.841 while C_b was 0.987 (Figure 1B). Similar results were obtained with sum of cons (CCC $0.9, \mathrm{r} 0.9, \mathrm{C} \_\mathrm{b} 0.996$ ) and sum of pros (CCC 0.89, r 0.90, C_b 0.99).

The Cohen's kappa values calculated for each single item ranged from 0.29 to 1 and the median value was 0.70 . According to Landis and Koch 1 (5\%) agreement could be considered fair, $5(25 \%)$ moderate and $14(70 \%)$ substantial or almost perfect.

\section{Comparison between patients and controls}

Discriminant analysis between patients and controls was performed at baseline; patients had statistically significant lower values of the DBI global score $(\mathrm{P}=0.0012)$, and the sum of cons and of pros was respectively higher than in controls. In patients the average of cons values was 22.1 (SD: 5.5) while in controls was 16.7 (SD: 4.7) $(\mathrm{P}=0.0011)$. The average of pros values was 30.7 (SD: 6.7) in cases $v s$ 17.2 (SD: 5.6) $(\mathrm{P}<0.001)$ in controls.

\section{Discussion and Conclusions}

Whenever individuals undertake a weight loss program, they impose on themselves specific goals, often impractical since targeted to an excessive reduction of body weight, in order to transform their image to improve their appearance, for reasons of health and fitness, but also simply to please others. ${ }^{25}$ From a behavior change viewpoint, avoiding an analysis on the detailed motives for initiating a weight loss program, individuals who attempt to lose weight have partially internalized pressuring forces and social constraints that value thinness above fatness. Many clinical models have been proposed to attend to motivational dynamics, such as motivational interviewing, the Socratic method, the transtheoretical model of change, and motivational enhancement therapy. Motivation is the key for treatment effectiveness (etymologically the word motivation derives from the Latin movere, that means to move or to be moved), because it determines how the patient becomes actively engaged and personally invested in change. A lack of motivation leading to poor adherence has been presented as a rationale for including motivation interview in weight control programs. ${ }^{26,27} \mathrm{~A}$ wellvalidated instrument for assessing self-motivation, which is suitable for weight control contexts, could help to elucidate situations where interventions are found to be non-optimal or ineffective in producing desirable weight loss outcomes and we strongly believe that DBI test could play a valuable role in this field.

The main purpose of the present research was to validate the Italian version of the DBI test. The results mainly suggest that the DBI is a reliable and valid instrument for the assessment of motivation in obese patients. The translation algorithm used a robust methodology that maxim linguistic accuracy and crosscultural adaptation; it has allowed us to elaborate an Italian version of DBI test, which sounded natural and easy to understand, minimizing all possible cultural bias. Since demographic and clinical features of the population included in this study may be considered representative of the general population of obese patients, our results may be comparable to those of the original version of the DBI validation studies in English language. Statistical tests have ascertained that the scores calculated on the test delivered at baseline are correlated with those detected during the second test administration, one week later. The Linn CCC reveals both precision and accuracy in collected data. If we consider the answers to single items, most of the results ( $70 \%$ ) showed a substantial or almost perfect agreement. As far as the comparison between patients and controls is concerned, the first showed statistically significant lower value of the DBI global score (at baseline, in patients $0.75 \pm 0.25 \mathrm{vs}$ $1.01 \pm 0.25$ in controls; after retest in patients $0.73 \pm 0.28$ vs $1.02 \pm 0.21$ in controls, while the sum of cons and of pros was respectively higher than in controls). The DBI is designed as an aid for psychologists and physicians at the initial assessment of the case, such as a source of suggestions, hypotheses and additional information. In clinical practice, therefore, the initial asse ssment of motivation is designed to collect all necessary data for identifying appropriate method of psychological intervention on the subject while the retest serves for an evaluation of the change. Therefore, this study tries to contribute to the existing literature offering a valid and reliable psychometric test, which could enable researchers and physicians to enhance the motivation of change in clinical practice.

Our study demonstrated the trans-cultural adaptation and validation of DBI test in Italian as a reliable and practicable instrument for motivation assessment; the DBI test has also proved to be a valuable tool for 
the study of cognitive aspects related to progression through the different stages of intentional change in weight loss.

\section{References}

1. Briggs M, Mueller CG, Fleischhacker S, et al. Position of the American Dietetic Association, School Nutrition Association, and Society for Nutrition Education: comprehensive school nutrition services. J Am Diet Assoc 2010;110:1738-49.

2. Sievenpiper JL, Dworatzek PD. Food and dietary pattern-based recommendations: an emerging approach to clinical practice guidelines for nutrition therapy in diabetes. Can J Diabetes 2013;37:51-7.

3. Mancia G, Fagard R, Narkiewicz K, et al. 2013 ESH/ESC Guidelines for the management of arterial hypertension: the Task Force for the management of arterial hypertension of the European Society of Hypertension (ESH) and of the European Society of Cardiology (ESC). J Hypertens 2013;31:1281-357.

4. Talwalkar PG, Sreenivas CG, Gulati A, et al. Journey in guidelines for lipid management: from adult treatment panel (ATP)-I to ATP-III and what to expect in ATP-IV. Indian J Endocrinol Metab 2013;17:628-35.

5. Perk J, De Backer G, Gohlke H, et al. European guidelines on cardiovascular disease prevention in clinical practice (version 2012): the fifth joint task force of the European society of cardiology and other societies on cardiovascular disease prevention in clinical practice (constituted by representatives of nine societies and by invited experts). Int J Behav Med 2012;19:403-88.

6. Shaw H, O'Rourke P, Del Mar C, Kenardy J. Psychological intervention for overweight or obesity. Cochrane Database Syst Rev 2005;18:CD003818.

7. Tsigos C, Hainer V, Basdevant A, et al. Management of obesity in adults: European Clinical Practice Guidelines. Obesity Facts 2008;1:106-16.

8. Prochaska JO, Velicer WF. The transtheoretical model of health behavior change. Am J Health Promot 1997; 12:38-48.

9. Velicer WF, Prochaska JO, Fava JL, et al. Using the transtheoretical model for population-based approaches to health promotion and disease prevention. Hom Health Dis 2000;40:174-95.

10. Hall KL, Rossi JS. Meta-analytic examination of the strong and weak principles across 48 health behaviors. Prev Med 2008;46:266-74.

11. Janis IL, Mann L. A psychological analysis of conflict, choice, and commitment. New York: Free Press; 1977.

12. O'connell D, Velicer WF. A decisional balance measure for weight loss. Int J Addictions 1988;23:729-50.

13. Ricca V, Mannucci E, Moretti S, et al. Screening for binge eating disorder in obese outpatients. Compr Psychiatry 2000;41:111-5.

14. Miotto P, De Coppi M, Frezza M, et al. Eating disorders and aggressiveness among adolescents. Acta Psychiatr Scan 2003;108:183-9.

15. A.N.S.I.S.A. (Associazione Nazionale Specialisti in Scienza dell'Alimentazione). Management methods section: Test di Valutazione del Comportamento Alimentare nell'Obeso (V.C.A.O.) Area somatica antropometricamotivazionale. Available from: http://www.ansisa.it/ template.php?pag $=46025$

16. Ware JE, Gandek B. Methods for testing data quality, scaling assumptions, and reliability: the IQOLA project approach. International quality of life assessment. J Clin Epidemiol 1988;51:945-52.

17. Meyer GJ. Guidelines for reporting information in studies of diagnostic test accuracy: the STARD initiative. J Pers Assess 2003;81:191-3.

18. Bullinger M, Alonso J, Apolone G, et al. Translating health status questionnaires and evaluating their quality: the IQOLA project approach. International quality of life assessment. J Clin Epidemiol 1998;51:913-23.

19. World Medical Association (WMA). WMA Declaration of Helsinki - Ethical principles for medical research involving human subjects; 1964-2008. Available from: http://www.wma.net/en/30publications/10policies/b3/ index.html

20. Cronbach LJ. Coefficient alpha and the internal structure of tests. Psychometr 1951;16:297-334.

21. Lin LIK. A concordance correlation coefficient to evaluate reproducibility. Biometr 1989;45:255-68.

22. Lin LIK. A note on the concordance correlation coefficient. Biometr 2000;56:324-5.

23. Cohen J. A coefficient of agreement for nominal scales. Educ and Psychol Meas 1960;20:37-46.

24. Landis JR, Koch GG. The measurement of observer agreement for categorical data. Biometr 1977;33:159-74.

25. Schwartz MB, Brownell KD. Obesity and body image. Body Image 2004;1:43-56.

26. Befort CA, Nollen N, Ellerbeck EF, et al. Motivational interviewing fails to improve outcomes of a behavioral weight loss program for obese African American women: a pilot randomized trial. J Behav Med 2008;31: 367-77.

27. Teixeira PJ, Going SB, Sardinha LB, et al. A review of psychosocial pre-treatment predictors of weight control. Obes Rev 2005;6:43-65. 